\title{
Legislación Electoral Argentina: evolución histórica
}

\author{
Argentine Electoral Legislation: historical \\ evolution
}

Legislação Eleitoral Argentina: evolução histórica

Législation électorale argentine: évolution bistorique

阿根廷选举立法:历史沿革

\author{
Diego Gabriel Presa ${ }^{1}$ \\ Universidad Nacional de La Plata - Argentina
}

Revista Derechos en Acción ISSN 2525-1678/ e-ISSN 2525-1686

Año 5/No 15 OTOÑO 2020 (21 marzo a 20 junio), 139-159

DOI: https://doi.org/10.24215/25251678e395

Recibido: 19/03/2020

Aprobado: 01/06/2020

Resumen: El presente abarca la legislación de los sistemas electorales y del voto en la República Argentina en el ámbito de la Nación, desde la primera ley dictada por la Confederación Argentina en la presidencia de Urquiza, con sus posteriores reformas, Ilegando al actual Código Electoral. Distintos momentos legales que acompañan el crecimiento institucional del país, así como su descenso a formas hoy inimaginables de fraudes y proscripciones electorales que son intolerables para los tiempos actuales.

Palabras clave: derecho electoral, legislación, historia constitucional.

Abstract: This article covers the legislation of the electoral and voting systems in the Argentine Republic at the national level, from the first law

\footnotetext{
Abogado, profesor de Historia Constitucional, cátedra III de la FCJ y S, asesor de la Honorable Cámara de Diputados de la Pcia de Bs As. (ORCID 0000-0003-3315-9301).
} 
enacted by the Argentine Confederation in the Urquiza presidency, with its subsequent reforms, to the current Electoral Code. Different legal moments that join the country's institutional growth, as well as its descent into forms of fraud today unimaginables, and electoral proscriptions that are intolerable for current times

Keywords: electoral law, legislation, constitutional history

Resumo: 0 presente trabalho engloba a legislação dos sistemas eleitorais e do voto na República Argentina no âmbito da Nação, desde a primeira lei emitida pela Confederação Argentina na presidência de Urquiza, com suas reformas subseqüentes, chegando o atual Código Eleitoral. Diferentes momentos jurídicos que acompanham o crescimento institucional do país, assim como seu descenso a formas hoje inimagináveis de fraude e proscrições eleitorais que são intoleráveis para os tempos atuais.

Palavras-chave: lei eleitoral, legislação, história constitucional.

Résumé: Le présent travail étudie la législation des systèmes électoraux et électoraux en République argentine, au niveau national. De la première loi promulguée par la Confédération argentine à la présidence d'Urquiza, avec ses réformes ultérieures, au Code électoral actuel. Des différents moments juridiques qui accompagnent la croissance institutionnelle du pays, ainsi que sa descente vers des formes de fraude et des interdictions électorales inimaginables aujourd'hui, qui sont intolérables pour l'époque actuelle

Mot-clés: loi électorale, législation, histoire constitutionnelle

摘要: 从阿根廷联邦在乌尔基萨总统任期内制定的第一部法律及其 随后的改革, 到目前的《选举法》, 本条款涵盖了国家范围内阿根廷 共和国选举和投票制度的立法. 该国的机构发展伴随着不同的法律 时刻, 以及其陷入当今无法想象的欺计和选举禁令的今天

关键词: 关键词选举法, 立法, 宪法史

\section{Introducción}

El presente tiene como objetivo clarificar la evolución del voto y los sistemas electorales que ha tenido la República Argentina a nivel nacional, lamentablemente nunca ha sido libre ese 
ejercicio de votar y muchas veces se ha visto interrumpido por procesos cívicos militares conocidos como golpes de Estado.

Tengamos presente algunas definiciones como por ejemplo sufragio, al que podemos definir como un derecho público subjetivo de naturaleza política, que detentan los integrantes de un Estado, para llevar adelante su organización y distribución del Poder dentro de dicha sociedad, donde hay electores y elegidos.

La Constitución Nacional en su artículo 37 establece “...Esta Constitución garantiza el pleno ejercicio de los derechos políticos, con arreglo al principio de la soberanía popular y de las leyes que se dicten en consecuencia. El sufragio es universal, igual, secreto y obligatorio. La igualdad real de oportunidades entre varones y mujeres para el acceso a cargos electivos y partidarios se garantizará por acciones positivas en la regulación de los partidos políticos y en el régimen electoral...", claramente lo ha dejado por escrito como un derecho político fundamental tendiente a la consolidación de la democracia, define al sufragio en su carácter hoy conocido y garantiza la igualdad de oportunidades entre varones y mujeres, muchas veces los derechos están solo nos falta exigir su cumplimiento.

Igualmente esta definición se acompaña de ciertos requerimientos para poder ejercer el derecho a sufragar, estas podemos distinguirlos en requerimientos generales y específicos, entre los primeros el requisito de ciudadanía o ciudadano del Estado, la ciudadanía se adquirirá según el estado por el nacimiento en el propio territorio o puede ser adquirida bajo una residencia de tiempo en el territorio; la edad para ejercer ese sufragio en la Argentina es voluntaria de dieciséis años a dieciocho y obligatoria de dieciocho a setenta años, volviendo a ser voluntaria a partir de esa edad, la obligatoriedad en una sociedad tan politizada como la nuestra le da legitimidad no solo al sistema sino también a los representantes elegidos.

Entre otros de los requisitos generales se encuentra la inscripción en el padrón electoral, integrar esa lista de electores tanto para elegir como para ser elegido que posibilitara el 
derecho a votar por una sola vez en la elección en un distrito o circunscripción electoral donde se encuentre inscripto, que es definido por el domicilio real.

El sexo del votante algo que se ha luchado a lo largo de la historia, comenzó siendo solamente para el universo masculino, con el tiempo y a mitad del Siglo XX se sumó el universo femenino por ley $\mathbf{1 3 0 1 0}^{2}$ de derechos políticos de la mujer, y ya en el Siglo XXI con la ley $\mathbf{2 6 . 7 4 3}^{3}$ se estableció el derecho a la identidad de género que permite a ser identificada la persona en los instrumentos que acreditan su identidad respecto de el/los nombre/s de pila, imagen y sexo con los que allí es registrada, entendiendo la ley por identidad de género a la vivencia interna e individual del género tal como cada persona la siente, la cual puede corresponder o no con el sexo asignado al momento del nacimiento, incluyendo la vivencia personal del cuerpo. Esto puede involucrar la modificación de la apariencia o la función corporal a través de medios farmacológicos, quirúrgicos o de otra índole, siempre que ello sea libremente escogido. También incluye otras expresiones de género, como la vestimenta, el modo de hablar y los modales, según el propio artículo $2^{\circ}$ de la misma.

Determinados los requerimientos generales, nos adentramos en los específicos, que están relacionados por la calidad del sufragio y por su extensión en lo que a universo se refiere. El sufragio se convierte en restringido o calificado, bajo condiciones intelectuales -sobre instrucción educativa, ejemplo saber leer y escribir- y sobre condiciones económicas -tener un ingreso determinado mensual o anual o profesión liberal- esto convierte al sistema de gobierno en oligárquico y fuera de la representación real del pueblo, siendo los terratenientes de grandes propiedades los que determinan la forma de composición del gobierno.

\footnotetext{
2 Publicada en el Boletín Oficial 27 de septiembre de 1947, Primer gobierno de Juan Domingo Perón 1946-1952.

3 Publicada en Boletín Oficial el 23 de mayo de 2012, Segunda Presidencia de Cristina Fernández de Kirchner 2011-2015
} 
La regla general es que el sufragio es único e individual, pero en algunas sociedades tenemos distintas clases de sufragios como el múltiple, el familiar, permitiendo que ciudadanos emitan más de un voto en su circuito electoral

Ahora otras características son las que determinan si el voto es público es decir que el mismo se emite a viva voz, con la dificultad que ese voto pueda ser coaccionado moral o físicamente hacia otro candidato o partido.

El voto secreto en contraposición al cantado, permite al elector elegir sin ser coaccionado al no saber a quién está eligiendo. Como un último requisito especifico tenemos su exigibilidad, en la Argentina actual es exigible a partir de los dieciocho años y hasta los setenta años, diferenciándolo del voto facultativo en el cual el derecho se entiende como voluntario de ser ejercido, a modo de ser repetitivo, insisto que en la sociedad Argentina, el voto debe ser obligatorio por la doble legitimidad que otorga el mismo al sistema de gobierno y al elegido para ejercer ese sistema mediante el poder que se le confiere.

\section{Leyes electorales nacionales}

En esta segunda etapa nos adentraremos en las leyes electorales nacionales que han regulado el voto y los sistemas electorales introducidos para conformar los poderes del Estado. No desarrollare los sistemas que existieron en las provincias antes de 1853. Llevare adelante un breve análisis de cada una de ellas en los temas que regularon y considero más importantes a mí criterio.

La primera ley electoral fue la número $\mathbf{1 4 0}^{4}$ dictada por el Congreso Nacional de la Confederación Argentina, -con Buenos Aires separada de la Confederación desde 1852- esta ley estableció el sistema electoral de lista completa, que significa esto que la primer minoría electoral electa ganaba todos los cargos en juego, no existiendo representación para la segunda y/o siguientes minorías en orden de votos decreciente.

4 Publicada el 16 de septiembre de 1857, en la presidencia de Justo José de Urquiza 1854-1860. 
Según la Constitución Nacional, los cargos a elegir de manera directa eran los diputados nacionales, indirectamente lo eran el presidente y vice mediante el Colegio Electoral, compuesto por el doble de diputados y senadores que integraban el Congreso, elegidos estos electores por la ciudadanía, se reunían en los colegios electorales de cada capital de provincia manifestando su voto por presidente y vice, el que mayor número de electores obtenía quedaba consagrado para desempeñar el Poder Ejecutivo Nacional.

La pregunta es ¿Cómo ejerzo mi derecho al voto en 1857?, primero los ciudadanos debían inscribirse en las Juntas Calificadoras que determinaba la ley, que llevaban a cargo el padrón o registro electoral, estaban eran integradas por funcionarios o por vecinos notables del lugar, con una actuación destacada del Juez de Paz. La inscripción era obligatoria pero no había sanción en caso de no hacerlo, esto conformaba lo que hoy sería un padrón electoral, este padrón o registro de electores se llevaba adelante antes de cada elección

Para emitir el voto se exigía la edad de veintiún años, excluyendo del voto a sordomudos; funcionarios eclesiásticos; y todo el que no fuera ciudadano de acuerdo a la ley.

El votante podía ejercer su derecho en forma verbal -voto cantado- o por escrito consignando el voto en forma pública, al ser leído por la autoridad de mesa en voz alta dejando constancia en una cedula electoral o lista al efecto.

El comicio se desarrollaba en unos tres días, el primero se organizaba las autoridades de mesa y comenzaba la votación, el horario para votar era entre las nueve horas y las dieciséis horas, teniendo presente la luz solar, cada día se hacía un escrutinio provisorio y ultimo día el definitivo que se comunicaba al Congreso Nacional para ser validado.

Esta ley fue modificada por la ley $207^{5}$, sancionada por el Congreso de la Confederación Argentina, determinando el voto

5 Publicada el 1 de julio de 1859, presidencia de Urquiza 1854-1860 
público no obligatorio, pero su vigencia seria corta, en noviembre de 1859 en la batalla de Cepeda Buenos Aires, se reincorporaba a la Confederación, una incorporación traumática, y justamente por al impugnación de los títulos de los diputados electos en 1861 y su rechazo por el Congreso Nacional al no haberse aplicado las leyes electorales vigentes a nivel nacional y utilizado las leyes provinciales, llevaron a un nuevo conflicto que culmino en la batalla de Pavón el 17 de septiembre de 1861, esto llevo a una nueva organización de la Republica bajo la órbita de la nueva clase dirigente porteña que impuso un nuevo modelo de nación en contraposición al modelo de la Confederación Argentina que venía desarrollándose, tan es así que las leyes comenzarían a enumerarse nuevamente.

El 1863 con el nuevo gobierno y orden establecido por Bartolomé Mitre $^{6}$, se sancionó una nueva ley electoral la número $7^{7}$ determinando la conformación del llamado Registro Cívico y la Asambleas Electorales, llevando al acto electoral a un día, el voto seguía siendo público y no obligatorio y bajaba la edad de veintiuno a dieciocho años siempre en el universo masculino, se agregaban excluidos del voto ahora a soldados y suboficiales -cabos y sargentos- así como a los que estén o tuvieran que estar enrolados en la guardia nacional.

Hubo una reforma menor con la ley $\mathbf{2 0 9}^{8}$, sobre los procedimientos a llevar adelante en el acto eleccionario.

La ley 623 ${ }^{9}$, determinando que el Registro Cívico o Padrón Electoral -debe tenerse en cuenta que se asemeja a un padrón pero no loes con las características actuales- se elaboraba cada cuatro años dejando sin efecto el anterior, era integrado por los ciudadanos con domicilio en la sección o circuito electoral que peticionaran integrar el mismo.

6 1821-1906, político, militar, historiador, periodista, fue gobernador de Buenos Aires y Presidente de la Nación constitucional en 1862-1868, fue Presidente de facto entre 1861-1862.

7 Publicada el 7 de noviembre de 1863, Presidencia de Bartolomé Mitre 1862 a 1868.

8 Publicada el 3 de octubre de 1866, Presidencia de Bartolomé Mitre 1862-1868

9 Publicada el 18 de septiembre de 1873, Presidencia de Domingo Faustino Sarmiento. 
La falta de transparencia en el desarrollo de los actos eleccionarios por parte de las autoridades llevo a la sanción de la ley $\mathbf{8 9 3}^{10}$, la cual fijo nuevos formas de funcionamientos para la Juntas Calificadoras en cuanto a su designación y conformación, prohibiendo desechar las actas de escrutinio que debían remitirse al Congreso Nacional conjuntamente con las protestas que se suscitaren en el acto electoral, la ley dejo sin efecto la exclusión para quien no hubiera cumplido su tiempo en la guardia nacional y debía hacerlo. Hubo diferentes modificaciones menores en cuanto a plazos y correcciones del Registro Cívico, esta ley sufrió modificaciones en los procedimientos y su aplicación entre 1879 y 1890 por las leyes 1012, 1024 y 2742, sin alterar el espíritu de la ley 893.

En 1902 Julio Argentino Roca ${ }^{11}$ y su Ministro del Interior Joaquín V González ${ }^{12}$, buscarían una alternativa al sistema electoral y al voto que permitiera oxigenar al régimen conservador, la oxigenación consistía en darle legitimidad y credibilidad al sistema, el cual era muy cuestionado por la posibilidad de fraude y manipulación.

La reforma electoral llevaría tranquilidad al campo social, permitiendo el ingreso de representantes de las minorías políticas que a la fecha no tenían expresión, modificando el sistema de lista completa imperante. El proyecto contemplaba el voto secreto pero las modificaciones del Senado dejaron de lado esta reforma manteniendo el voto público.

Finalmente se convirtió en la ley $\mathbf{4 1 6 1 ^ { 1 3 }}$, la misma estableció el sistema minoritario uninominal por circunscripciones,

\footnotetext{
10 Publicada el 8 de octubre de 1877, Presidencia de Nicolás Avellaneda 1874 a 1880

11 1843-1914, político, militar argentino, ideólogo de la llamada Conquista del Desierto, dos veces presidente entre 1880-1886 y 1898-1904, ocupó diversos cargos públicos en el Poder Ejecutivo y Legislativo.

12 1863-1923, político, docente y jurista argentino, gobernador de La Rioja entre 1889-1891, fue ministro y legislador, transformo en nacional la Universidad de La Plata

13 Publicada en el Boletín Oficial el 29 de enero de 1903, Segunda presidencia de Julio A. Roca 1898-1904
} 
fijo nuevamente la edad para votar en dieciocho años, a fin de garantizar el voto los electores no podían ser detenidos durante las horas del acto comicial, salvo caso de flagrante delito, ni obligado a dar su voto por otro candidato que el de su preferencia. La legitimidad como elector se acreditaba con la libreta cívica.

El territorio del Estado Nacional para la elección de diputados al Congreso, así como electores de Senadores Nacionales por la ciudad Capital y electores de Presidente y Vice Presidente de la Nación, se dividía en distritos electorales, que a su vez se subdividían en circunscripciones igual al número de Diputados que elegían, eligiendo cada una un Diputado nacional, dos electores de Presidente y Vice de la Nación y en la ciudad Capital cuatro electores por el duplo del número de Senadores.

El sistema se aplicó para el comicio de 1904 y posibilito la elección de Alfredo Palacios ${ }^{14}$ por el partido Socialista.

En 1905 y con Manuel Quintana ${ }^{15}$ como nuevo presidente impulsó un retorno a la antigua ley derogándose la ley 4161 por la ley $4578^{16}$ complementada por la ley $4719^{17}$ volviendo al sistema de lista completa, derogando las circunscripciones uninominales, además el elector al emitir su voto, presentando su libreta cívica, adjuntaría una lista o boleta que contendría los nombres de las personas por quienes votaba, así se mantenía el voto público y se pensaba que se evitaba el fraude al no poder ser influido el elector si venía con los nombres ya escritos de sus elegidos.

El sistema conservador estaba en su agonía, pero no se disponía a cambiar para mejorar, se aferraba a sus privilegios, la muerte del Presidente Manuel Quintana en el cargo en 1906

14 1878-1965, abogado, legislador, político y profesor de la UBA y UNLP, integrante del Partido Socialista.

15 1835-1906, abogado y político argentino, presidente de la Nación en 1904-1906 falleció en el cargo.

16 Publicada en el Boletín Oficial el 26 de julio de 1905, Presidencia de Manuel Quintana 1904-1906.

17 Publicada en el Boletín Oficial el 9 de octubre de 1905, Presidencia de Manuel Quintana 1904-1906. 
y la asunción de José Figueroa Alcorta ${ }^{18}$ quien se enfrentó al roquismo y en 1910 apoyo la elección de Roque Sáenz Peña ${ }^{19}$ como Presidente de la Nación, este designo como Ministro del Interior a Indalecio Gómez ${ }^{20}$, y juntos comenzaron a impulsar un nuevo sistema electoral y un nuevo voto.

El cambio requería de varias leyes se comenzó con la ley $\mathbf{8 1 2 9}^{21}$ de enrolamiento general de todo ciudadano nativo o naturalizado a partir de los dieciocho años, a cargo de las autoridades militares y del Registro Civil, con una libreta de enrolamiento de que servía para identificarse y con un domicilio real valido consignado, a la que se sumaba la ley $\mathbf{8 1 3 0}^{22}$ de formación del padrón electoral encargando la formación del mismo a los jueces federales, quienes designaban a un comisario de padrón, que no era empleado público y estaba encargado de llevar adelante el mismo, tomaba como base cada año el registro de enrolamiento militar, había un periodo de impugnaciones y rectificaciones del padrón por parte de particulares, se autorizaba a utilizar la libreta de enrolamiento para ejercer el voto y de las resoluciones que dictaren los jueces federales cualquiera fuera su resultado, se podrían apelar ante al Cámara Federal correspondiente.

Ambas leyes llevaron a un nuevo registro o padrón electoral amplio de la ciudadanía, lo que posibilito tratar por el Congreso ahora el proyecto que se convertirá en la ley $\mathbf{8 8 7 1}^{23}$ la misma

18 1860-1931, abogado y político argentino, ocupó la presidencia de los tres poderes del Estado Vicepresidente de la Nación y como consecuencia directa Presidente del Senado entre 1904-1906, Presidente de la Nación de 1906 a 1910 y presidente de la Corte Suprema de Justicia de la Nación Argentina entre 1929-1931.

19 1851-1914, abogado y político argentino, Presidente de la Nación entre 1910-1914 falleció en el cargo.

20 1850-1920, jurista y político argentino, defensor de la ley electoral ante el Congreso Nacional.

21 Publicada el 4 de julio de 1911, Presidencia de Roque Sáenz Peña 1910-1914

22 Publicada el 19 de julio de 1911, Presidencia de Roque Sáenz Peña 1910-1914

23 Publicada en el Boletín Oficial el 26 de marzo de 1912, Presidencia de Roque Sáenz Peña 1910-1914. 
se dividía en diez títulos con diferentes capítulos, comenzaba con los electores incluidos a votar desde los dieciocho años y hasta los setenta años de edad inclusive, los excluidos del voto, se dividían en tres grandes grupos, por incapacidad: a) Los dementes declarados en juicio; b) Los sordomudos que no sepan hacerse entender por escrito. Por su estado y condición: a) Los eclesiásticos regulares; b) Los soldados, cabos y sargentos del ejército permanente y armada y agentes o gendarmes de policía; c) Los detenidos por juez competente, mientras no recuperen su libertad; d) Los dementes y mendigos, mientras estén recluidos, en asilos públicos y en general, todos los que se hallen asilados en hospicios públicos o estén habitualmente a cargo de congregaciones de caridad. Por indignidad: a) Los reincidentes condenados por delito contra la propiedad, durante cinco años después de cumplida la sentencia; b) Los penados por falso testimonio o por delitos electorales durante cinco años; c) Los que hubieran sido declarados, por autoridad competente, incapaces de desempeñar funciones políticas; d) Los quebrados fraudulentos hasta su rehabilitación; e) Los que hubiesen sido privados de la tutela o curatela, por defraudación de los bienes del menor o del incapaz, mientras no restituyan lo adeuda; f) Todos aquellos que se hallen bajo la vigencia de una pena temporal, hasta que ésta sea cumplida; g) Los que hubiesen eludido las leyes sobre el servicio militar, hasta que hayan cumplido la pena que le corresponde; h) Los que hubiesen sido excluidos del ejército con pena de degradación o por deserción, hasta diez años después de la condena; i) Los deudores por apropiación o defraudación de caudales públicos, mientras no satisfagan su deuda; j) Los dueños y gerentes de prostíbulos.

El sufragio se consideraba individual (art $5^{\circ}$ ), el titulo tercero regulaba la convocatoria a elecciones y el título cuarto de los colegios electorales y su formación.

El capítulo IV hablaba del sufragio, la elección comenzaba a las ocho de la mañana y terminaba a las dieciocho horas de la tarde el mismo día, donde se regulaba la forma de votar, el orden, la permanencia de hasta diez personas dentro del lugar de 
votación, la identificación del elector por el presidente de mesa a través de la libreta de enrolamiento y de no ser impugnada su identidad, se le entregaba un sobre firmado por la autoridad de mesa y lo invitaba a pasar a una habitación continua -cuarto oscuro- a encerrar su voto, de esta forma se establece el voto secreto (art $39^{\circ}$ ), en la habitación vacía solo habría boletas de cada partido o candidato, entregadas al presidente del comicio por los apoderados, en el padrón una vez emitido el voto se anotaba delante del nombre "votó", finalizado el acto a la hora de cierre el Presidente cubría la urna, en su abertura, con una hoja de papel fuerte que sellaría, firmaría y haría firmar por los presentes apoderados de los candidatos, dejando constancia de los que se nieguen a hacerlo.

Debía tachar los nombres de los electores que no hayan comparecido y dejar constancia en el padrón el número de electores que sufragaron en el acto y de las protestas que se hubieren producido, las urnas se entregan al correo quien las remitía a las juntas escrutadoras que funcionaban en cada capital de provincia y en el Capital Federal.

En el titulo sexto se determinaba el nuevo sistema electoral donde cada elector sólo podrá votar por las dos terceras partes del número a elegir en la elección ocurrente, esto significaba pasar al modelo de lista incompleta, el candidato o partido ganador obtendría dos tercios de los cargos en disputa y el candidato o partido en segundo lugar el tercio restante, no se contemplaba el candidato o partido que obtenía el tercer o cuarto lugar, igualmente la ley era un avance en calidad institucional.

A fin de evitar amedrentamientos el titulo noveno prohibía la aglomeración de tropas en el radio del comicio, se prohibía a los funcionarios públicos exigir afiliaciones o que voten por candidatos determinados, durante las horas de comicio, quedan prohibidos los espectáculos populares al aire libre, o en recintos cerrados, fiestas teatrales, deportivas y toda otra clase de reuniones públicas que no se refieren al acto electoral, se prohibía la venta de bebidas alcohólicas durante el día del comicio y hasta una hora después del mismo. 
Se establecía pena de pecuniaria al elector que no emitiera su voto sin causa legítima que lo amparara.

La ley que había llevado una ardua discusión parlamentaria había logrado el voto secreto, individual, universal -solo abarca el universo de varones- y obligatorio con un nuevo sistema electoral de lista incompleta.

La ley permitió ampliar la base de votantes y la legitimidad de los gobernantes, funciono mientras fue respetada y hasta el 6 de septiembre de 1930 con el golpe cívico militar que abrió la denominada década infame.

En 1936 el Congreso sanciono la ley $\mathbf{1 2 2 9 8}^{24}$ modificando el artículo 55 de la ley 8871 en cuanto a los electores de Presidente y Vice Presidente de la Nación, electores a Senadores Nacionales por parte de la Capital Federal, y la elección de Diputados Nacionales, se realizara bajo el mecanismo de lista completa, excluyendo a las minorías del Congreso.

En 1947 el Congreso Nacional y a instancias de Eva Perón ${ }^{25}$ sancionara la ley $\mathbf{1 3 0 1 0}^{26}$ que establece los mismos derechos políticos para las mujeres que el que detentan los varones, estableciendo la libreta cívica como documento de identidad indispensable para todos los actos civiles y electorales y se ordenaba dentro de los dieciocho meses de sancionada la ley la confección del padrón femenino. La ley se aplicara por primera vez en la elección presidencial de 1951.

En 1951 se sanciono otra reforma electoral bajo la ley $\mathbf{1 4 0 3 2}^{27}$ que restableció el sistema de las circunscripciones uninominales exclusivamente para la elección de Diputados

\footnotetext{
24 Publicada en el Boletín Oficial el 5 de agosto de 1936, Presidencia de Agustín P Justo 1932-1938

25 1919-1952, su nombre es María Eva Duarte de Perón, dirigente política argentina, luchadora de las causas sociales.

26 Publicada en el Boletín Oficial el 13 de septiembre de 1947, Primera presidencia de Juan Domingo Perón 1946-1952.

27 Publicada en el Boletín Oficial el 18 de julio de 1951, Primera presidencia de Juan Domingo Perón 1946-1952.
} 
Nacionales. Eliminaba el Colegio Electoral para la elección de presidente y vice, estableciendo el sistema directo, al igual que los senadores nacionales.

En 1957 y con el golpe cívico militar instalada desde septiembre de 1955, el gobierno de facto dicto el decreto $\mathbf{4 0 3 4 / 1 9 5 7 ^ { 2 8 }}$ que derogo la ley 14032, restableciendo la ley 8871 -Sáenz Peña- con sistema de lista incompleta nuevamente, fue comple-

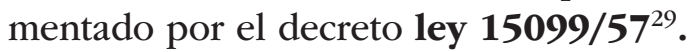

En marzo de 1962, en elecciones legislativas y de Gobernadores, se instrumentó por decreto $7164 / 62$, que adopta el método D'Hondt el cual se establece el sistema de representación proporcional para electores de presidente y de senadores por la Capital, y para senadores, quedando fuera del reparto de cargos las listas que no obtuvieren un piso del tres por ciento, que será dejado sin efecto por el Congreso Nacional mediante ley $\mathbf{1 6 5 8 2}^{30}$.

El gobierno cívico militar de 1972 dicto la ley $19945^{31}$ que estableció el Código Electoral Nacional, que se encuentra vigente, con distintas modificaciones a la actualidad, la ley se compone de ocho títulos y se subdivide cada título en capítulos, entre las leyes que lo han modificado o complementado las más importantes están la ley 26215 ley de financiamiento de los partidos políticos, la ley 26743 -citada- sobre identidad de género; ley $\mathbf{2 6 7 7 4}$ de ciudadanía y $\mathbf{2 7 4 1 2}$ paridad de género, haciendo realidad el texto del artículo 37 de la Carta Magna.

Entre sus principales regulaciones la edad de dieciséis años para argentinos nativos o por opción, y de dieciocho años para argentinos naturalizados.

\footnotetext{
28 Publicado en el Boletín Oficial el 25 de abril de 1957, Presidencia de facto de Pedro Aramburu 1955-1958.

29 Publicado en el Boletín Oficial el 22 de noviembre de 1957, Presidencia de facto de Pedro Aramburu 1955-1958.

30 Publicada en el Boletín Oficial el 1 de diciembre de 1964, Presidencia de Arturo Illia 19631966

31 Publicada en el Boletín Oficial el 19 de diciembre de 1972, Presidencia de facto de Alejandro Lanusse 1971-1973.
} 
Entre los excluidos de votar se detallan a los siguientes: a) Los dementes declarados tales en juicio; b) Los condenados por delitos dolosos a pena privativa de la libertad, y, por sentencia ejecutoriada, por el término de la condena; c) Los condenados por faltas previstas en las leyes nacionales y provinciales de juegos prohibidos, por el término de tres años; en el caso de reincidencia, por seis; d) Los sancionados por la infracción de deserción calificada, por el doble término de la duración de la sanción; e) Los declarados rebeldes en causa penal, hasta que cese la rebeldía o se opere la prescripción; f) Los inhabilitados según disposiciones de la Ley Orgánica de los Partidos Políticos, y g) Los que en virtud de otras prescripciones legales y reglamentarias quedaren inhabilitados para el ejercicio de los derechos político.

El artículo 12 establece quienes deben votar como regla general y deja exentos de esa obligación los siguientes: a) Los jueces y sus auxiliares que por imperio de esta ley deban asistir a sus oficinas y mantenerlas abiertas mientras dure el acto comicial; b) Los que el día de la elección se encuentren a más de quinientos kilómetros del lugar donde deban votar y justifiquen que el alejamiento obedece a motivos razonables. c) Los enfermos o imposibilitados por fuerza mayor, suficientemente comprobada, que les impida asistir al acto, y d) El personal de organismos y empresas de servicios públicos que por razones atinentes a su cumplimiento deban realizar tareas que le impidan asistir al comicio durante su desarrollo.

Hay un Registro Nacional de electores que contiene los electores por distrito; los electores inhabilitados y excluidos; los electores residentes en el exterior y los electores privados de la libertad.

El padrón electoral provisorio contendrá número y clase de documento cívico, apellido, nombre y domicilio de los inscritos, el cual tiene un periodo una vez cerrado para rectificaciones o correcciones.

Luego se confeccionar el padrón electoral definitivo el cual estará impreso treinta días antes de la elección, pudiendo los 
electores hasta veinte días antes del acto comicial, solicitar se subsanen los errores y omisiones existentes.

El titulo segundo establece las divisiones territoriales, la Ciudad Autónoma y cada Provincia son los distritos electorales, que se subdividen en secciones electorales, los circuitos, que serán subdivisiones de las secciones.

Se establece una Junta Electoral Nacional en cada capital de provincia y la Ciudad Autónoma, entre sus atribuciones están: 1) Aprobar las boletas de sufragio; 2) Decidir sobre las impugnaciones, votos recurridos y protestas que se sometan a su consideración; 3) Resolver respecto de las causas que a su juicio fundan la validez o nulidad de la elección; 4) Realizar el escrutinio del distrito, proclamar a los que resulten electos otorgarles sus diplomas; 5) Nombrar al personal transitorio y afectar al de la secretaría electoral con arreglo a lo dispuesto en el artículo anterior; 6) Realizar las además tareas que le asigne esta ley y 7) Llevar un libro especial de actas en el que se consignará todo lo actuado en cada elección.

Los partidos políticos deben designar apoderados quienes son sus representantes ante la Junta Electoral, los candidatos quedaran proclamados hasta cincuenta días antes de la elección, las boletas a utilizar deben ser oficializadas como mínimo treinta días antes a la fecha del comicio.

La ley $27337^{32}$ que es texto ordenado del Código Electoral, estableció el inicio de campaña electoral cincuenta días antes de la fecha determinada de votación, el debate obligatorio, la publicidad se establece treinta y cinco días antes a la elección, también regulo el debate presidencial obligatorio.

Dentro del comienzo del comicio que se desarrollara entre las ocho de la mañana y las dieciocho horas sin interrupción.

Se prohíbe según el artículo $71^{\circ}$ : a) reuniones de electores o depósito de armas durante las horas de la elección; b) Los

32 Publicada en el Boletín Oficial el 13 de diciembre de 2016, Presidencia de Mauricio Macri 2015-2019 
espectáculos populares al aire libre o en recintos cerrados, fiestas teatrales, deportivas y toda clase de reuniones públicas que no se refieran al acto electoral, durante su desarrollo y hasta pasadas tres horas de ser clausurado; c) la prohibición de venta de bebidas alcohólicas hasta transcurridas tres horas del cierre del comicio; d) Ofrecer o entregar a los electores boletas de sufragio dentro de un radio de ochenta metros de las mesas receptoras de votos; e) A los electores, la portación de armas, el uso de banderas, divisas u otros distintivos durante el día de la elección, doce horas antes y tres horas después de finalizada; f) Realizar actos públicos de proselitismo y publicar y difundir encuestas y sondeos preelectorales, cuarenta y ocho horas antes de la iniciación del comicio y hasta el cierre del mismo. g) La apertura de organismos partidarios dentro de un radio de ochenta metros de las mesas receptoras de votos; h) Publicar o difundir encuestas y proyecciones sobre el resultado de la elección durante la realización del comicio y hasta tres horas después de su cierre.

Las autoridades de mesas se designan en forma aleatoria (art $72^{\circ}$ ) y deben tener domicilio dentro de la sección electoral de la mesa asignada y son designados por la Justicia Electoral, se pueden excusar con causa justa en el plazo de tres días de notificados, igualmente la ley ha creado un registro público de autoridades de mesa.

El capítulo III, determina todo el desarrollo del acto electoral desde su inicio, recepción de urna, los útiles remitidos por el Estado dentro de la urna, la conformación del cuarto oscura, los modelos de boletas validas, así como las actas de apertura y cierre que serán firmadas por todos y en caso de negarse se consignara en la misma.

El artículo $84^{\circ}$ establece que los primeros en votar serán las autoridades de la mesa, en caso de que el presidente o sus suplentes no se hallen inscriptos en la mesa en que actúan, se agregará el nombre del votante en la hoja del registro haciéndolo constar, así como la mesa en que está registrado. El voto tiene carácter de secreto $\left(\operatorname{art} 85^{\circ}\right)$. 
Cada elector votara una vez identificado con su documento nacional de identidad, en caso de impugnación de la identidad del elector, el artículo $91^{\circ}$ determina que se expondrá concretamente el motivo de la impugnación, labrándose un acta firmada por el presidente y el o los impugnantes y tomándose nota sumaria en la columna de observaciones del padrón, frente al nombre del elector.

El voto se emite mediante sobre cerrado entregado por la autoridad de mesa al elector y una vez emitido entregara una constancia del mismo al elector.

En el título V, se establece la forma de escrutinio el presidente del comicio, auxiliado por los suplentes, con vigilancia policial o militar en el acceso y ante la sola presencia de los fiscales acreditados, apoderados y candidatos que lo soliciten, mediante el procedimiento determinado por ley: 1 $^{\circ}$ ) Abrir la urna, extrayendo todos los sobres, los cuenta y confronta con el número de votantes; $\mathbf{2}^{\circ}$ ). Examinará los sobres, separando los que estén en forma legal y los que correspondan a votos impugnados; 3) Practicadas tales operaciones procederá a la apertura de los sobres; 4) Luego separando los sufragios para su recuento en las siguientes categorías: a) Votos válidos: que son los emitidos mediante boleta oficializada, aun cuando tuvieren tachaduras de candidatos, agregados o sustituciones, será válida una boleta por sobre, destruyendo las repetidas.

Los votos nulos serán los emitidos por boletas no oficializadas, boletas de distintos partidos en un mismo sobre; boletas donde no se puedan distinguir candidato y categoría a elegir y boletas con objetos extraños a ella. Los votos en blanco son el sobre vacío o papel de algún color. Los votos recurridos son los cuestionados en su validez o nulidad por alguno fiscal el cual se consigna en un sobre especial al efecto y será resuelto el mismo por la Junta Electoral. Los votos impugnados son sobre dudas de la identidad del elector.

Finalizado se confecciona el acta de escrutinio, donde debe quedar registrado lo siguiente: a) La hora de cierre del comicio, 
número de sufragios emitidos, cantidad de votos impugnados, diferencia entre las cifras de sufragios escrutados y la de votantes señalados en el registro de electores; todo ello asentado en letras y números; b) Cantidad también en letras y números de los sufragios logrados por cada uno de los respectivos partidos y en cada una de las categorías de cargos; el número de votos nulos, recurridos y en blanco; c) El nombre del presidente, los suplentes y fiscales que actuaron en la mesa, el fiscal que se ausente antes de la clausura del comicio suscribirá una constancia de la hora y motivo del retiro y en caso de negarse a ello se hará constar esta circunstancia firmando otro de los fiscales presentes; d) La mención de las protestas que formulen los fiscales sobre el desarrollo del acto eleccionario; e) La nómina de los agentes de policía, individualizados con el número de chapa, que se desempeñaron a órdenes de las autoridades del comicio hasta la terminación del escrutinio; f) La hora de finalización del escrutinio; g) la autoridad de mesa emitirá un "Certificado de Escrutinio" que será suscripto por el mismo, por los suplentes y los fiscales y entregará uno cada fiscal que ha participado por partido político dejando constancia en el acta de los certificados expedidos a cada parte.

Por último el cierre de la urna lleva un certificado de escrutinio dentro de ella y otro fuera entregando la urna faja, sellada y firmada por todos los participantes al personal del Correo, que serán auxiliados por la fuerza policial y militar en cuanto a su custodia.

El escrutinio definitivo queda a cargo de la Junta Electoral ante la cual los partidos o agrupaciones podrán designar fiscales o apoderados para que los representen, las mesas que no sean cuestionados por los fiscales y apoderados y los certificados de escrutinio coincidan con los expedidos se confirmaran, las mesas cuestionadas y que los certificados coincidan no se procederá a su apertura, solo se abrirán las mesas donde los certificados expedidos por las autoridades de mesa no coincidan con él de la propia mesa. No existiendo más impugnaciones o reclamos la Junta Electoral proclamara a los electos. 
El título VI determina las penas por infracciones a la ley electoral desde multas por la no emisión del voto, a penas de prisión por ejemplo portación de armas.

En el título VII regula la elección de Presidente y Vice, Senadores Nacionales, Diputados Nacionales y de los parlamentarios del Mercosur.

Entre las disposiciones generales el artículo $167^{\circ}$, establece la vigencia de la Libreta de Enrolamiento (Ley 11.386 ${ }^{33}$ ), la Libreta Cívica (Ley 13.010) y el Documento Nacional de Identidad (D.N.I.), en cualquiera de sus formatos (Ley 17.671 ${ }^{34}$ ) todos documentos habilitantes a los fines de ejercer el voto.

El Código Electoral ha sido mejorado en el tiempo y por la democracia, no olvidemos que dicho código tiene nacimiento como ley de un gobierno de facto, los distintos textos ordenados han sido fruto del consenso democrático y que reflejan los cambios exigidos por la sociedad, claro que es perfectible, todas las leyes hechas por mujeres y hombres lo son.

\section{Conclusiones}

El camino recorrido por el sistema electoral no es casual, podemos ver que comienza con un inicio que prefiero llamar de consolidación, pero no se consolidad el sistema electoral, sino la clase dirigente, quien opondrá excusa tras excusa para no permitir un sistema electoral sólido y con la no posibilidad de votar, las distintas reformas solo intentaran consolidar el poder de la clase dirigente conservadora ya, que ha ocupado el poder político y económico no dando muestras de querer dejarlo. Es en 1910 cuando parte de esa clase dar un giro a su política enfrentándose entre ellos mismos y posibilita la expresión real del pueblo a través de un voto universal, secreto, obligatorio e

33 Publicada en el Boletín Oficial el día 25 de octubre de 1926, Presidencia de Marcelo T de Alvear 1922-1928

34 Publicada en el Boletín Oficial el 12 de marzo de 1968, Presidencia de facto de Juan Carlos Ongania 1966-1970 
individual, el mismo permitirá la llegada de las nuevas mayorías a ejercer el poder político, como serán los gobiernos radicales de 1916 a 1930.

La nueva democracia se verá truncada el 6 de septiembre de 1930 por el golpe cívico militar y con él volverán a ocupar el poder la clase conservadora que pretende recuperar los privilegios que había perdido mediante el voto popular, pero esta vez mediante el fraude escandaloso y la violencia, fraude que será interrumpido por un nuevo golpe cívico militar en 1943, una nueva era del voto popular se instala en la Republica y aparece la Argentina de masas, es conocido el periodo 1955 a 1983, con distintas interrupciones cívico militares a los gobiernos elegidos por el pueblo, con proscripciones políticas, sumando en la última etapa la desaparición forzosa de personas que pensaran distinto.

En 1983 y con el ejercicio del sufragio Argentina recupera la democracia, hoy ya con 37 años de democracia ininterrumpida, con modificaciones a las leyes electorales que pretenden adentrarnos en este Siglo XXI y no olvidar, pero si dejar atrás malas prácticas del Siglo XX, hay un avance en calidad institucional que consolida esta democracia recuperada y ganada que tanto nos ha costado, objetivos como la libertad, la libertad de expresión, la distribución de la riqueza, la igualdad de oportunidades, el disenso y la discusión para arribar a consensos, el crecimiento con inclusión, son faros que no debemos perder para arribar a una mejor sociedad y a una mayor democracia.

\section{Bibliografía consultada}

Fraquelli, Ileana (2013). Código Electoral Nacional concordado y comentado. segunda ed., Buenos Aires, Platense.

Gelli, María Angélica (2005). Constitución de la Nación Argentina, comentada y concordada, Buenos Aires, La Ley..

López, Mario Justo (1973). Manual de derecho político. Buenos Aires, Kapelusz. 